Cita bibliográfica. Fernández Ortea, J. (2017). Análisis cuantitativo del impacto del arqueoturismo en España. Investigaciones Turisticas (14), pp. 87-108. http://dx.doi.org/10.14461/INTURI2017.14.05

\title{
Análisis cuantitativo del impacto del arqueoturismo en España
}

\section{Quantitative analysis of the impact of archaeological tourism in Spain}

Javier Fernández Ortea. Monasterio de Monsalud y ciudad romana de Ercávica (Castilla-La Mancha). Arqueólogo y antropólogo. javierfernandezortea@gmail.com

\section{RESUMEN}

Este trabajo se centra en el análisis cuantitativo de la realidad turística de los yacimientos arqueológicos atendiendo a la necesidad de conocer un recurso patrimonial en crecimiento. También se pretende evaluar el impacto de este fenómeno en el conjunto global y su situación particular en el mapa autonómico. Metodológicamente el estudio se basa en datos oficiales aportados por los agentes implicados en la gestión de los diversos enclaves vía telefónica y telemática. Con el conjunto de la información recopilada se han elaborado mapas que ilustran el volumen de visitas y, por ende, su aportación al turismo general. En definitiva, una radiografía del arqueoturismo, un recurso que deja de ser una alternativa minoritaria para ser protagonista de una importante parcela del turismo cultural.

Palabras clave: Arqueoturismo, turismo arqueológico, turismo alternativo, yacimiento arqueológico.

\section{ABSTRACT}

This study constitutes a quantitative analysis of the tourism situation of archaeological sites in response to the need to recognise a growing heritage resource. It also seeks to evaluate the impact of this phenomenon on tourism as a whole and its particular situation on a regional level. In terms of methodology, the study is based on official data provided by the agents involved in the management of the sites by telephone and online. With the set of collected information, maps have been produced that illustrate the volume of visits and, therefore, their contribution to overall tourism. In short, it provides an $\mathrm{x}$-ray of archeotourism; a resource that is no longer a minority alternative and is starting to play a major role in a significant part of cultural tourism.

Keywords: Archeology, archaeological tourism, alternative tourism, archaeological site.

\section{INTRODUCCIÓN}

El presente artículo atiende a la necesidad de responder a un simple interrogante ¿Qué papel desempeñan los yacimientos y espacios arqueológicos en el turismo español? Nos estamos refiriendo al número de visitantes $y$, por tanto, volumen económico para un espacio geográfico concreto que ejerce de anfitrión. En esta premisa, se trata de dar una aproximación cuantitativa al fenómeno del arqueoturismo, un sector minoritario pero en 
progresivo aumento. Conocer la dimensión de su impacto en el turismo es un primer paso para llevar a cabo estrategias de planificación, promoción y desarrollo.

La posición general de partida destaca por la opacidad en las cifras, sólo publicadas en los medios de comunicación como ejemplos de una exitosa política en centros de entidad. La noticia sirve así como telón propagandístico en mayor medida que informadora de una realidad actual. Cabe citar como meritoria excepción el caso de Andalucía, publicando anualmente en su Estadística de la Red de Espacios Culturales de Andalucía el número neto de visitantes a los yacimientos arqueológicos de competencia de la Junta. Precisamente será este aspecto, la propugnada competencia concurrente en materia de cultura (Art.46 Constitución), la que haga que la gestión de los yacimientos sea tan diversa y habitualmente poco transparente.

Es frecuente encontrar testimonios que defienden el papel del patrimonio cultural como motor de desarrollo (Peinado Herreros, 2012) y el arqueológico en particular (MartínBueno y Luesma, 2006). Dicho desarrollo puede ser en una vertiente educativa, social o económica. Si entendemos el patrimonio arqueológico como motor de desarrollo o dinamizador, estamos hablando de la capacidad que tiene éste de regenerar un tejido social y darle nuevas oportunidades de promoción económica. Para evaluar la validez de esta afirmación es imprescindible conocer la realidad de los yacimientos arqueológicos como recursos turísticos, único parámetro de estimar su dimensión económica.

El patrimonio arqueológico se ubica, predominantemente, en espacios rurales, premisa que puede ser utilizada como acicate a entornos deprimidos. Si entendemos por turismo rural "la actividad turística de implantación sostenible en el medio rural (Traverso 1996, p.38)", es fácil conjugar la apuesta por la preservación del patrimonio con el futuro de nuestros pueblos. Además, el agotamiento del modelo de turismo de sol y playa debe combinarse con otros mercados complementarios de índole cultural y paisajística que enriquezcan la experiencia del visitante. La tendencia en viajes es la búsqueda de sensaciones originales, únicas y auténticas, por ello, pocos productos son tan evocadores como los restos arqueológicos. Por último, el Informe de hábitos turísticos de los residentes en España (2007), arroja estadísticas que invitan al optimismo; El 56,2\% de los individuos residentes en España realizan alguna vez una excursión. El 34,2\% realiza viajes de fin de semana y dentro de esa porción el $69,0 \%$ lo hace en todas las épocas del año. Por último, el $25,4 \%$ tiene como principal motivación para viajar los destinos culturales. En este sentido, podemos constatar el carácter flexible del excursionismo, en el que se puede incluir el sector arqueológico en gran medida, respecto a la acusada estacionalidad de otro tipo de turismos.

Este análisis pretende responder a la necesidad de calibrar el potencial atractivo del turismo arqueológico en una localidad o región, en la medida de lo posible, siendo una herramienta útil para planificar estrategias globales en cada territorio. 


\section{ESTADO DE LA CUESTIÓN}

A nivel global, la UNESCO ha destacado en atender la compatibilidad de la conservación del patrimonio con el turismo desde la década de los noventa. Este organismo ha publicado numerosos estudios con recomendaciones generales (Feilden y Jokilehto, 1993) y referidas a espacios concretos declarados patrimonio de la Humanidad (Wager, 1995). Sus trabajos han procurado crear directrices y modelos de buenas prácticas por encima de otras consideraciones cuantitativas (Pedersen, 2002).

En el mundo anglosajón pronto cristalizó el interés por conocer las preferencias y percepciones del público en relación al patrimonio y los yacimientos arqueológicos. Se trata de un enfoque lógico en un ámbito con un mayor peso del ámbito privado en estos sectores. En Norteamérica se contempla la clasificación del público que visita centros arqueológicos (McManamon, 1991), su percepción (Pokotylo y Guppy, 1999) y su impacto económico (Poor y Smith, 2004) desde hace décadas.

En Europa se distingue la postura oficial de las autoridades y administraciones del ámbito académico. En la primera se ofrecen estudios estadísticos de los principales centros gestionados por entidades públicas. Este es el caso del ELSTAT (Hellenic Statistical Authority), institución que publica mensualmente los datos de visitantes a los principales yacimientos arqueológicos y museos afines del país heleno.

En Francia, el gobierno nacional facilita al usuario un listado geográfico de los yacimientos arqueológicos sin identificar, y las actividades realizadas por aquellos que son visitables. Los estudios de público galos se centran en espacios concretos y las posibilidades de desarrollo aparejadas (Lugand, 2000; Reynaud; 1990; Gillot, 2007). Al igual que en el caso español, la mayor fuente informativa en cifras es el estudio anual de la situación cultural confeccionado por el Ministère de la Culture et de la Communication. En Portugal, Pablo Raposo ha publicado un inventario de trescientos yacimientos arqueológicos visitables en el país lusitano (2001), primer paso para un estudio sistematizado de su repercusión turística.

En España, las referencias bibliográficas disponibles se orientan a estudios monográficos locales de dinamización turística (López y Navarro, 2007; Chavez et al., 20092010 y Moreno, 2013). Se centran en el plano de gestión o divulgación, con algunas obras de conjunto (Ballart y Tresserras, 2001; Querol, 2010, Ponce y Rubio, 2013). Cabe desestimar en este ámbito la cuestión turística y su potencial a nivel económico, razón que justifica la publicación de éste estudio. De forma genérica, los investigadores han separado el ámbito del conocimiento científico del turismo en la arqueología, cuando ambos son indisolubles. La investigación fomentó el conocimiento de culturas pasadas y éstas al ser reveladas fueron objeto de protección en museos y en sus propias sedes por el interés que despertaban en el turismo (Díaz-Andreu, 2014). Esta afirmación debe entenderse en los conjuntos arqueológicos clásicos como Egipto o Grecia. Sin embargo, la gran mayoría del patrimonio arqueológico al servicio del turismo es un fenómeno reciente. El exponencial incremento del turismo busca nuevos nichos para ocupar el tiempo de ocio del viajero y el turismo arqueológico es uno de ellos (González, 1997, p.290).

El turismo arqueológico es aún muy joven, por lo que aún está copado por el sector público. En la actualidad, está en proceso de aumentar la presencia privada como medio de 
diversificar mercado y aumentar la competitividad de la oferta cultural (Velasco, 2009, p.242).

La mayor aproximación al patrimonio arqueológico como recurso visitable nos es facilitada por Morère y Jiménez en un estudio de técnicas cualitativas con participación de diversas administraciones de Cultura y Patrimonio en el marco del proyecto HIRYT (Morère y Molinero, 2006). La desigual respuesta de las instituciones implicadas minó la muestra del universo, pero dejó interesantes reflexiones acerca de la postura de éstas respecto al arqueoturismo. Los cuestionarios diseñados atendían a vislumbrar la política de puesta en valor y promoción de los yacimientos arqueológicos, así como los modelos de gestión de los mismos. Fuera de nuestras fronteras, en Brasil, el estudio de Manzato y Rejowski (2007) propone la creación de escalas de adecuación turística en yacimientos en función de unos índices numéricos.

Del mismo modo, nos gustaría llamar la atención sobre la escasez de estudios de público en yacimientos arqueológicos en España, destacando la investigación de archivo en Carmona (Rodríguez et al., 2015), del comportamiento del visitante en Medina Azahara (García y Calle, 2010) y la percepción y calidad del servicio en Itálica (Martín-Ruiz et al, 2010). Las motivaciones principales para visitar estos enclaves han sido objeto de atención, destacando la búsqueda de experiencias memorables que evadan, eduquen y entretengan (Recuero et al., 2010). Asimismo, los autores anteriores se hacen eco de ciertos factores que influyen decisivamente en la afluencia de público tales como equipamiento, la presencia de exposiciones temporales, riqueza natural y la cercanía a otros productos turísticos.

\section{METODOLOGÍA}

Al inicio de este estudio parecía casi inviable la obtención de información precisa de tantas administraciones implicadas; Ministerio de Cultura, 19 autonomías, una ciudad autónoma, 8 diputaciones, 4 diputaciones forales, siete cabildos insulares y un Consejo insular. A ello habría que sumar un importante número de ayuntamientos y otras entidades de derecho público y privado tales como consorcios, fundaciones, oficinas de turismo y empresas. Sin duda esta polifacética gerencia dificultaba el acceso a los datos.

Un segundo escollo suponía la profusión y ambigüedad del fenómeno arqueológico en nuestro país. En el primer aspecto, debe aclararse que la cantidad de yacimientos y centros arqueológicos es muy abundante, producto tanto de campañas de excavación como por su estado en la naturaleza -caso de pinturas rupestres, grabados o monumentos-. Dicha abundancia ha implicado que seleccionemos una muestra representativa del universo disponible, discriminando los yacimientos sin acceso al público, señalética ni control de visitantes. Aunque algunos sí han sido registrados en el plano correspondiente para dejar testimonio de su existencia, no hemos recogido todos por su desinterés para la investigación, ya que no aportaban datos cuantitativos de visitantes. Los yacimientos de libre acceso, sin instalaciones o servicios de guía, quedan por tanto, excluidos del estudio pese a que no debamos infravalorar su potencial. Por otra parte, el hecho de que carezcan de un personal de mantenimiento y exhibición pública da cuenta de que tienen un seguimiento discreto en cifras en la actualidad. Por otra parte, los museos y centros de interpretación de temática exclusivamente arqueológica han sido atendidos en función de su interés, pero han sido desestimados los centros provinciales por acoger colecciones de otras naturalezas artísticas. 
El siguiente obstáculo supone la compleja acotación de lo que entendemos por arqueológico, definido este como el patrimonio susceptible de ser estudiado con metodología arqueológica (Art.40 Ley Ley/1985 de PHE). En el presente análisis hemos decidido incluir los lugares que han sido objeto de campañas sistemáticas de excavación o que son espacios históricos visitables que han sido musealizados o señalizados, excluyendo patrimonio inmueble, industrial y etnológico con algunas excepciones justificadas.

La metodología empleada ha consistido en encuestas orales y por escrito a los responsables y/o titulares de los yacimientos y centros arqueológicos incluidos en todo el territorio nacional. Se les requería la cifra de visitantes totales en el ejercicio 2015 a efectos de llevar a cabo un estudio a nivel nacional del impacto del turismo arqueológico en nuestro país. La solicitud, formalizada por escrito a través de un email, venía aparejada a un recordatorio de la Ley 19/2013, de transparencia, acceso a la información pública y buen gobierno que la amparaba. El uso de este recurso forzaba en mayor medida a la respuesta, entendiéndose como un derecho ciudadano que debía ser atendido. El éxito en la recogida de datos se debe en gran parte a ésta medida, junto al trato personalizado.

La recopilación de información fue una tarea laboriosa que implicó un trabajo de unos siete meses para recoger toda la muestra presentada, esfuerzo no exento de sucesivos intentos hasta alcanzar los objetivos marcados. En relación a la ponderación de los datos registrados, la estimación de la cifra que compone el universo es desconocida ya que no podemos conocer la totalidad del fenómeno del arqueoturismo. En este sentido, debemos objetar que no es factible documentar con rigurosidad todos los yacimientos arqueológicos y centros afines que conforman la Población en nuestro país. Pese a ello, si podemos afirmar con rotundidad que la muestra seleccionada es representativa del arqueoturismo en España. Nos basamos en el hecho de que hemos recogido una muestra no probabilística, sino total de todos los yacimientos y centros de interpretación vinculados de gestión autonómica y provincial, siendo además muy amplia en relación a la porción local y privada. El acceso a yacimientos y espacios arqueológicos en ámbitos de baja escala, necesariamente, tendrán un sesgo en la muestra por desconocer todos los espacios de éste ámbito. De cualquier modo, en este caso son habitualmente lugares de libre acceso que no podrían proporcionar información adicional al presente estudio.

\section{ANÁLISIS DE LOS DATOS OBTENIDOS}

A partir de las cifras recopiladas en la tarea previa de documentación hemos podido elaborar las siguientes tablas y mapas de dispersión de arqueoturistas: 
Tabla 1. Índice de impacto turístico de los yacimientos arqueológicos

\begin{tabular}{lccccc}
\hline \multicolumn{1}{c}{ CCAA } & $\begin{array}{c}\text { Turismo Total } \\
\mathbf{2 0 1 4}\end{array}$ & Arqueoturismo & $\begin{array}{c}\text { Porcentaje de } \\
\text { Impacto }\end{array}$ & $\mathbf{k m}^{\mathbf{2}}$ & $\begin{array}{c}\text { Densidad } \\
\text { Km/yac. } \\
\text { visitable }\end{array}$ \\
\hline Andalucía & 31.878 .360 & 1.416 .904 & $4,45 \%$ & 87.599 & $0,0034 \%$ \\
\hline Aragón & 7.928 .531 & 146.788 & $1,85 \%$ & 47.720 & $0,029 \%$ \\
\hline Asturias & 4.500 .215 & 251.289 & $5,58 \%$ & 10.604 & $0,160 \%$ \\
\hline Baleares & 13.728 .813 & 224.484 & $1,63 \%$ & 4.992 & $0,235 \%$ \\
\hline Canarias & 16.388 .496 & 299.309 & $1,82 \%$ & 7.447 & $0,174 \%$ \\
\hline Cantabria & 3.453606 & 360.052 & $1,04 \%$ & 5.321 & $0,187 \%$ \\
\hline Castilla La-Mancha & 11.239 .721 & 115.576 & $1,02 \%$ & 79.463 & $0,017 \%$ \\
\hline Castilla y León & 16.610 .819 & 771.797 & $4,64 \%$ & 94.222 & $0,053 \%$ \\
\hline Cataluña & 37.417 .775 & 3.237 .839 & $8,6 \%$ & 32.113 & $0,143 \%$ \\
\hline C.Valenciana & 22.856 .381 & 439.704 & $1,92 \%$ & 23.255 & $0,098 \%$ \\
\hline Extremadura & 4.650 .480 & 838.007 & $18,01 \%$ & 41.634 & $0,048 \%$ \\
\hline Euskadi & 4.757 .875 & 98.846 & $2,07 \%$ & 7.234 & $0,110 \%$ \\
\hline Galicia & 7.610 .231 & 208.836 & $2,74 \%$ & 29.574 & $0,054 \%$ \\
\hline Madrid & 13.667 .288 & 28.633 & $0,209 \%$ & 8.030 & $0,161 \%$ \\
\hline Murcia & 3.666 .483 & 442.282 & $12,06 \%$ & 11.313 & $0,106 \%$ \\
\hline Navarra & 2.895 .687 & 18.513 & $0,63 \%$ & 10.391 & $0,057 \%$ \\
\hline La Rioja & 1.412 .767 & 11.663 & $0,82 \%$ & 5.045 & $0,059 \%$ \\
\hline Ceuta & 80.6992 & 16.046 & $19,88 \%$ & 18,5 & $5,4 \%$ \\
\hline \multicolumn{1}{c}{ TOTAL } & & 8.926 .568 & & & \\
\hline
\end{tabular}

Elaboración propia

Figura 1. Gráfico porcentual del arqueoturismo por comunidad autónoma

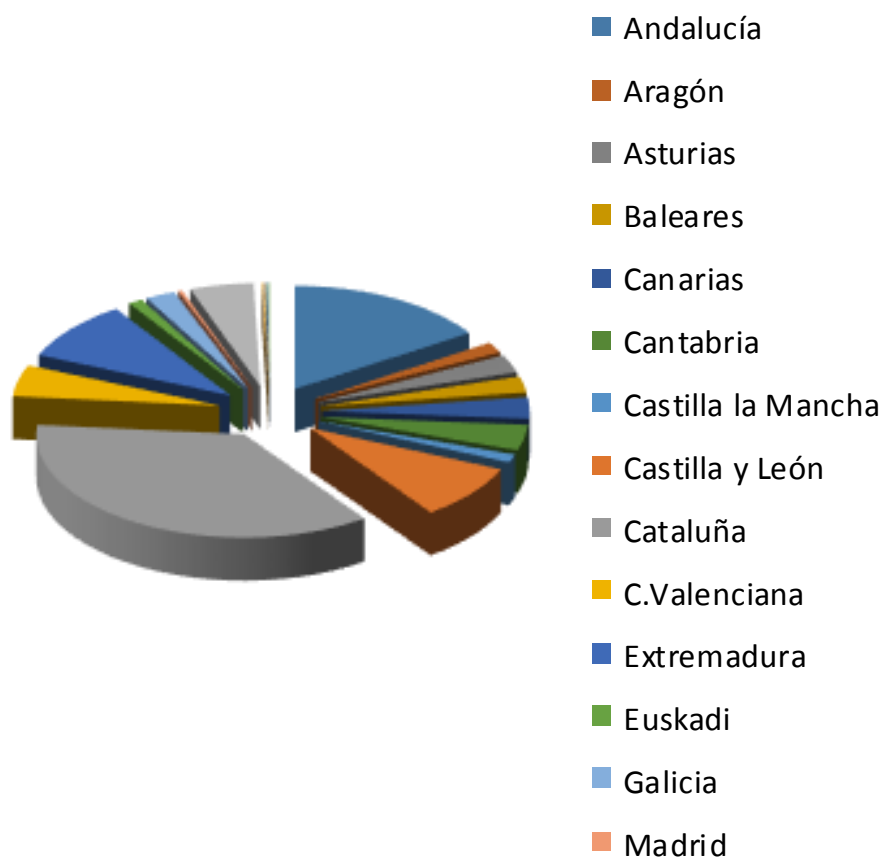

Elaboración propia

\footnotetext{
${ }^{1}$ Datos del último año suministrados por el INE, turismo nacional (Informe Familitur) y extranjero (Informe Frontur). Sobre Ceuta el dato fue facilitado por la oficina de turismo local ya que no está incluida en los estudios del INE.

${ }^{2}$ Información obtenida del Anuario Estadístico de Ceuta 2012 de Procesa. 
Tabla 2. Yacimientos arqueológicos más visitados en 2015

\begin{tabular}{|c|c|c|c|c|}
\hline $\begin{array}{c}\text { Yacimiento } \\
\text { Conjunto }\end{array}$ & CCAA & Visitantes & $\begin{array}{l}\text { Impacto } \\
\text { Turístico }\end{array}$ & Cronología \\
\hline El Born 3 & Cataluña & 1.851502 & $4,94 \%$ & Moderna \\
\hline Conjunto de Tarraco & Cataluña & 560.724 & $1,49 \%$ & Antigua \\
\hline $\begin{array}{l}\text { Conjunto Mérida y Museo Arte } \\
\text { Romano }\end{array}$ & Extremadura & 489.431 & $10,52 \%$ & Antigua \\
\hline Museo de la Evolución Humana ${ }^{4 * *}$ & Castilla y León & 370.466 & $2,23 \%$ & Prehistoria \\
\hline Teatro Málaga & Andalucía & 341.025 & $1,06 \%$ & Antigua \\
\hline Barcino & Cataluña & 331.194 & $0,88 \%$ & Antigua \\
\hline Altamira & Cantabria & 263.753 & $7,6 \%$ & Prehistórica \\
\hline Conjunto de Cartagena & Murcia & 262.621 & $7,1 \%$ & Antigua \\
\hline Alcazaba de Almería & Andalucía & 230.236 & $0,72 \%$ & Medieval \\
\hline Medina Azahara & Andalucía & 169.768 & $0,53 \%$ & Medieval \\
\hline Itálica & Andalucía & 148.449 & $0,46 \%$ & Antigua \\
\hline Ampurias & Cataluña & 139.227 & $0,43 \%$ & Antigua \\
\hline Poblado de Ifach & C.Valenciana & 130.000 & $0,56 \%$ & Medieval \\
\hline Caesaragusta & Aragón & 115.943 & $1,46 \%$ & Antigua \\
\hline Dolmen de Antequera & Andalucía & 106.583 & $0,33 \%$ & Prehistórica \\
\hline Teatro de Sagunto & C.Valenciana & 78.497 & $0,34 \%$ & Antigua \\
\hline TOTAL & & 5.589 .419 & $40,65 \%$ & \\
\hline
\end{tabular}

Elaboración propia.

Tabla 3. Yacimientos arqueológicos con mayor impacto turístico en 2015

\begin{tabular}{lcccc}
\hline \multicolumn{1}{c}{$\begin{array}{c}\text { Yacimiento } \\
\text { Conjunto }\end{array}$} & CCAA & Visitantes & $\begin{array}{c}\text { Impacto } \\
\text { Turístico }\end{array}$ & Cronología \\
\hline Conjunto Mérida y Museo Romano & Extremadura & 489.431 & $10,52 \%$ & Antigua \\
\hline Altamira & Cantabria & 263.753 & $7,6 \%$ & Prehistórica \\
\hline Conjunto de Cartagena & Murcia & 262.621 & $7,1 \%$ & Antigua \\
Museo de la Evolución Humana & Castilla y León & 370.466 & $2,23 \%$ & Prehistoria \\
\hline Tarraco & Cataluña & 560.724 & $1,49 \%$ & Antigua \\
Caesaraugusta & Aragón & 115.943 & $1,46 \%$ & Antigua \\
\hline T.Bustillo & Asturias & 59.847 & $1,32 \%$ & Prehistórica \\
El Castillo & Cantabria & 37.742 & $1,09 \%$ & Prehistórica \\
\hline Termas Campo Valdés & Asturias & 48.569 & $1,07 \%$ & Antigua \\
\hline Teatro Málaga & Andalucía & 341.025 & $1,06 \%$ & Antigua \\
Campa Torres & Asturias & 44.702 & $0,99 \%$ & Antigua \\
Barcino & Cataluña & 331.194 & $0,88 \%$ & Antigua \\
\hline Alcazaba de Almería & Andalucía & 230.236 & $0,72 \%$ & Medieval \\
Ekain & Euskadi & 30.000 & $0,63 \%$ & Prehistórica \\
\hline Poblado de Ifach & C.Valenciana & 130.000 & $0,56 \%$ & Medieval \\
\hline Medina Azahara & Andalucía & 169.768 & $0,53 \%$ & Medieval \\
\hline Itálica & Andalucía & 148.449 & $0,46 \%$ & Antigua \\
\hline Segóbriga & Castilla la Mancha & 49.317 & $0,43 \%$ & Antigua \\
\hline Atapuerca & Castilla y León & 67.197 & $0,40 \%$ & Prehistoria \\
\hline
\end{tabular}

Elaboración propia.

\footnotetext{
${ }^{3}$ Debería tomarse este dato con precaución, ya que la motivación de los visitantes no tiene porqué ser la arqueología ya que está inserto en un centro cultural.

${ }^{4}$ Entendemos este museo como un centro arqueológico.
} 


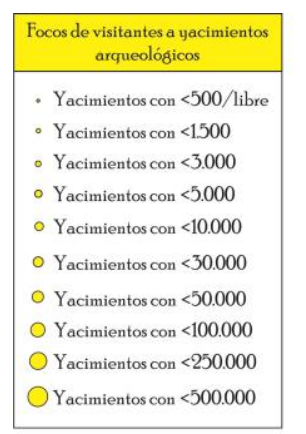

Figura 2. Mapa del arqueoturismo en España.

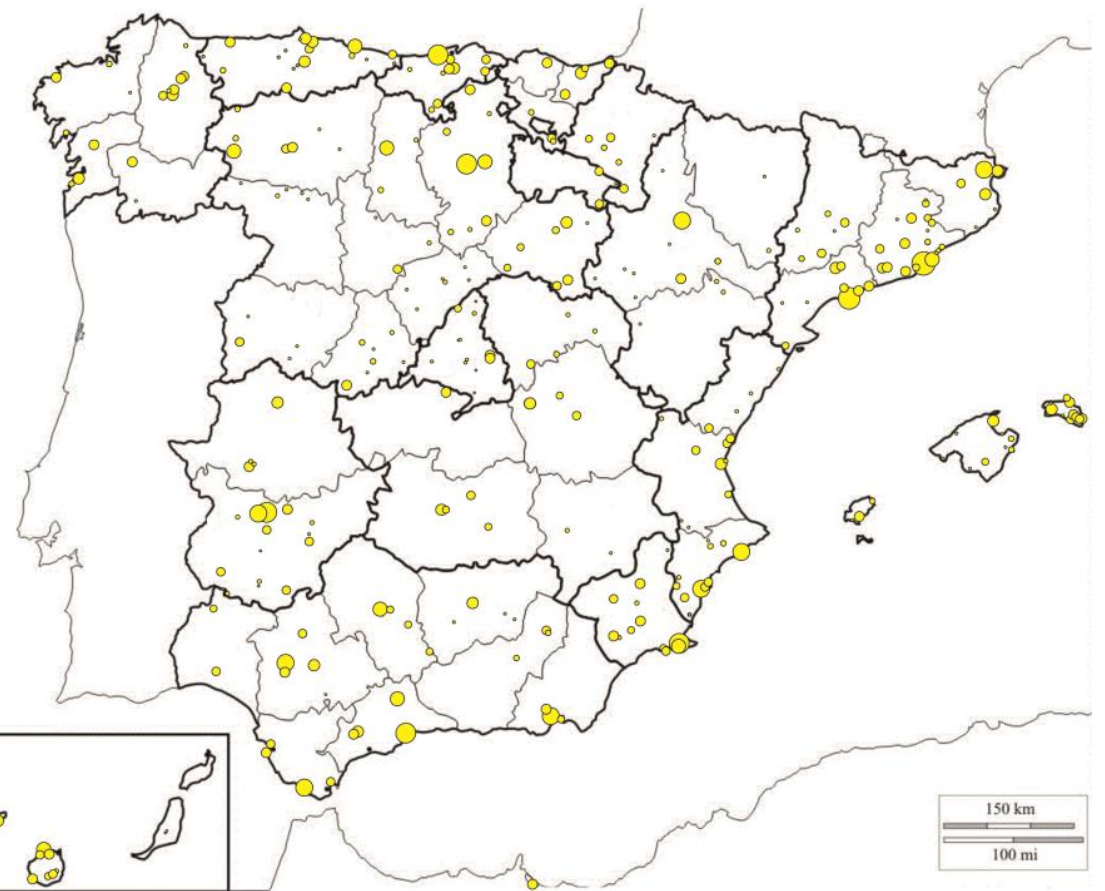

Elaboración propia.

Figura 3. Sur de España: Andalucía y Murcia.

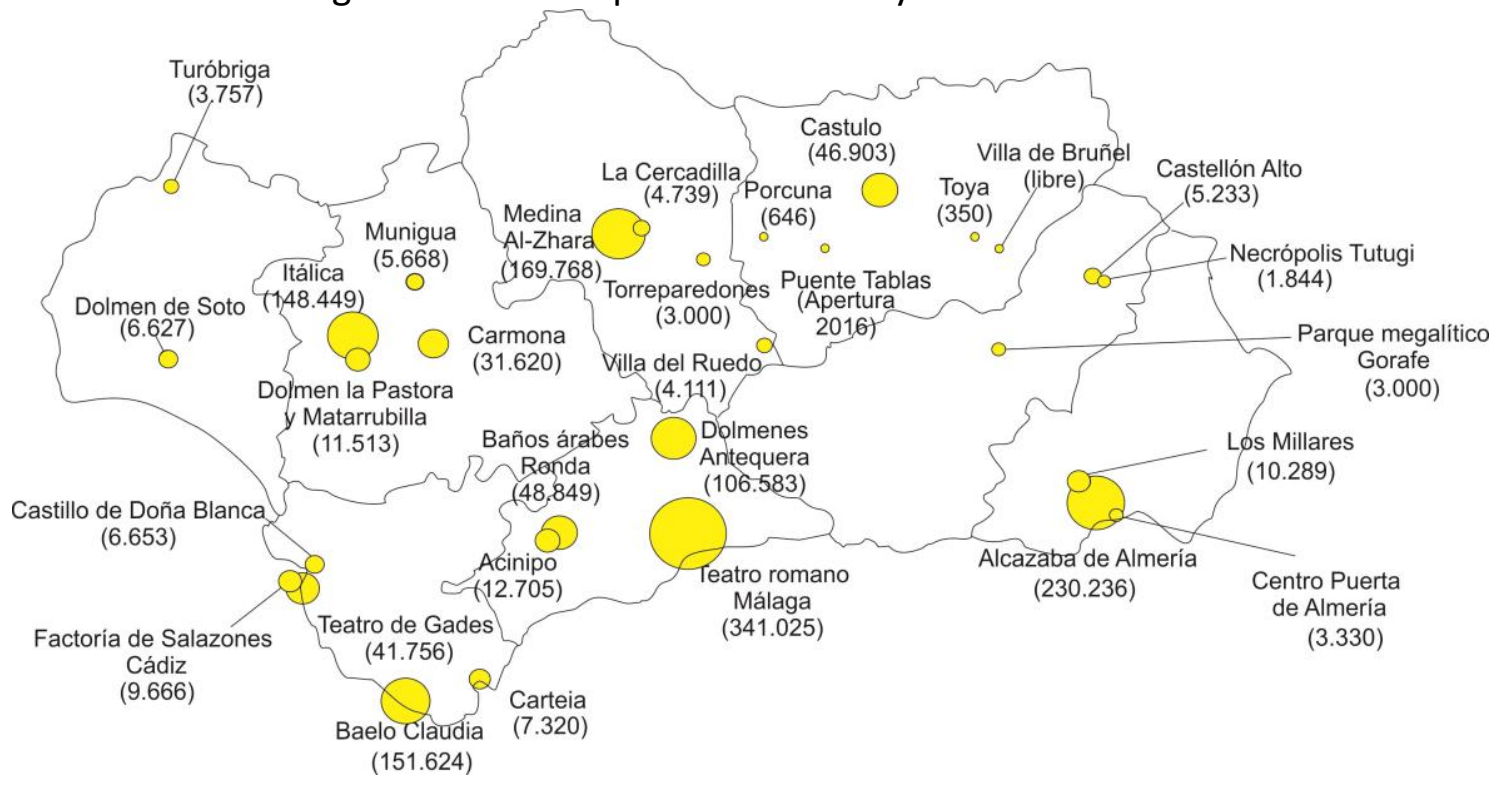




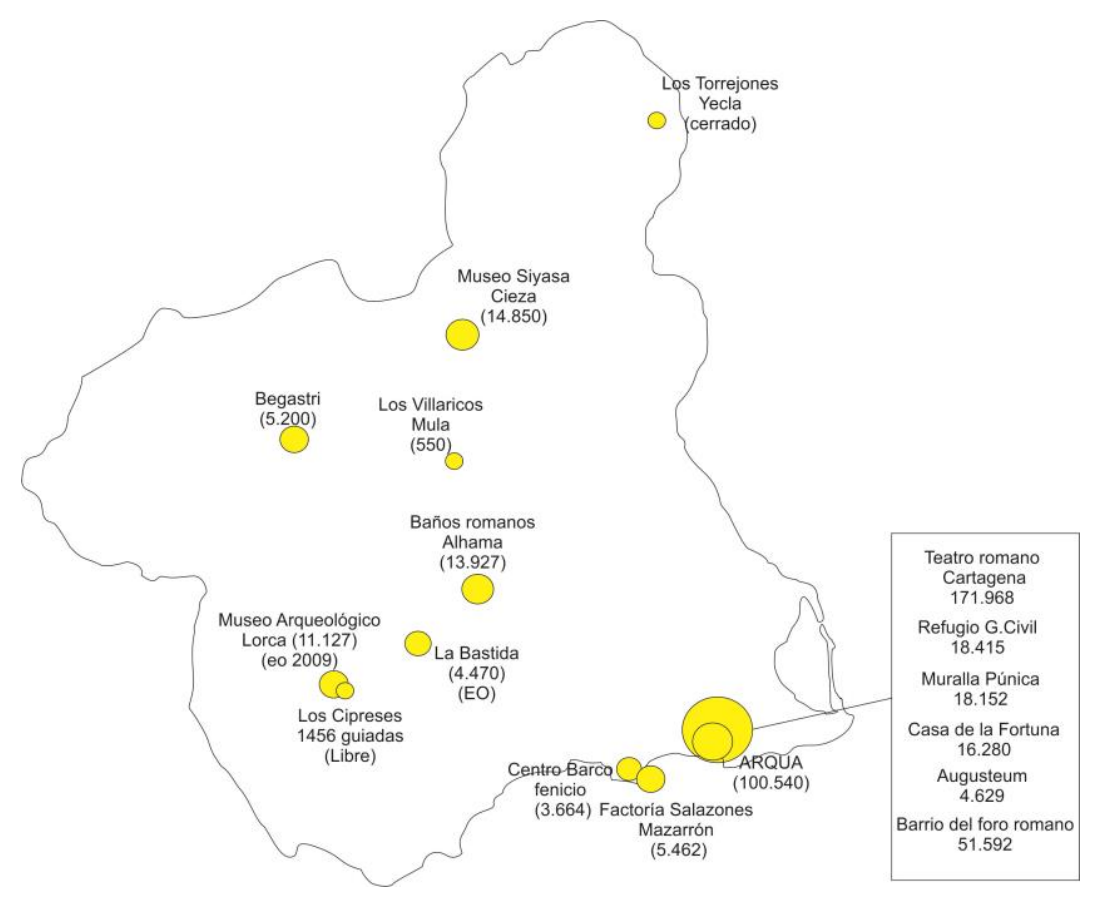

Elaboración propia.

Figura 4. España interior: Extremadura, Aragón, Madrid, Castilla la Mancha y Castilla y León

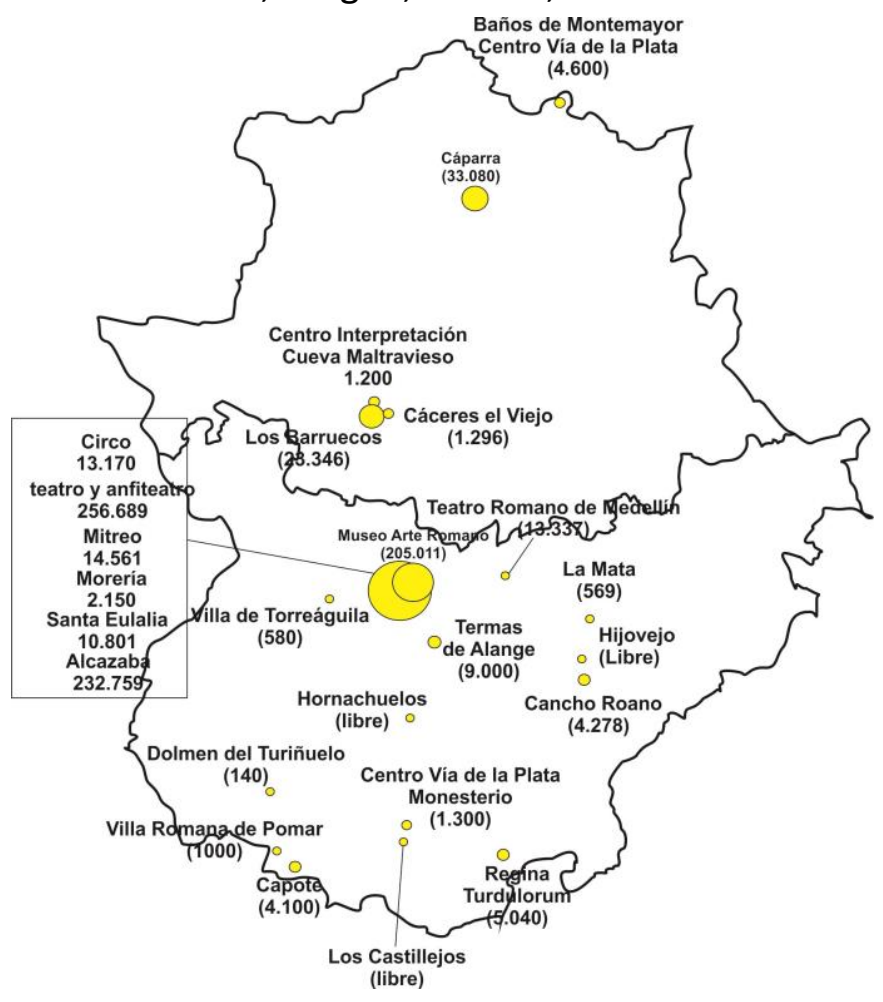




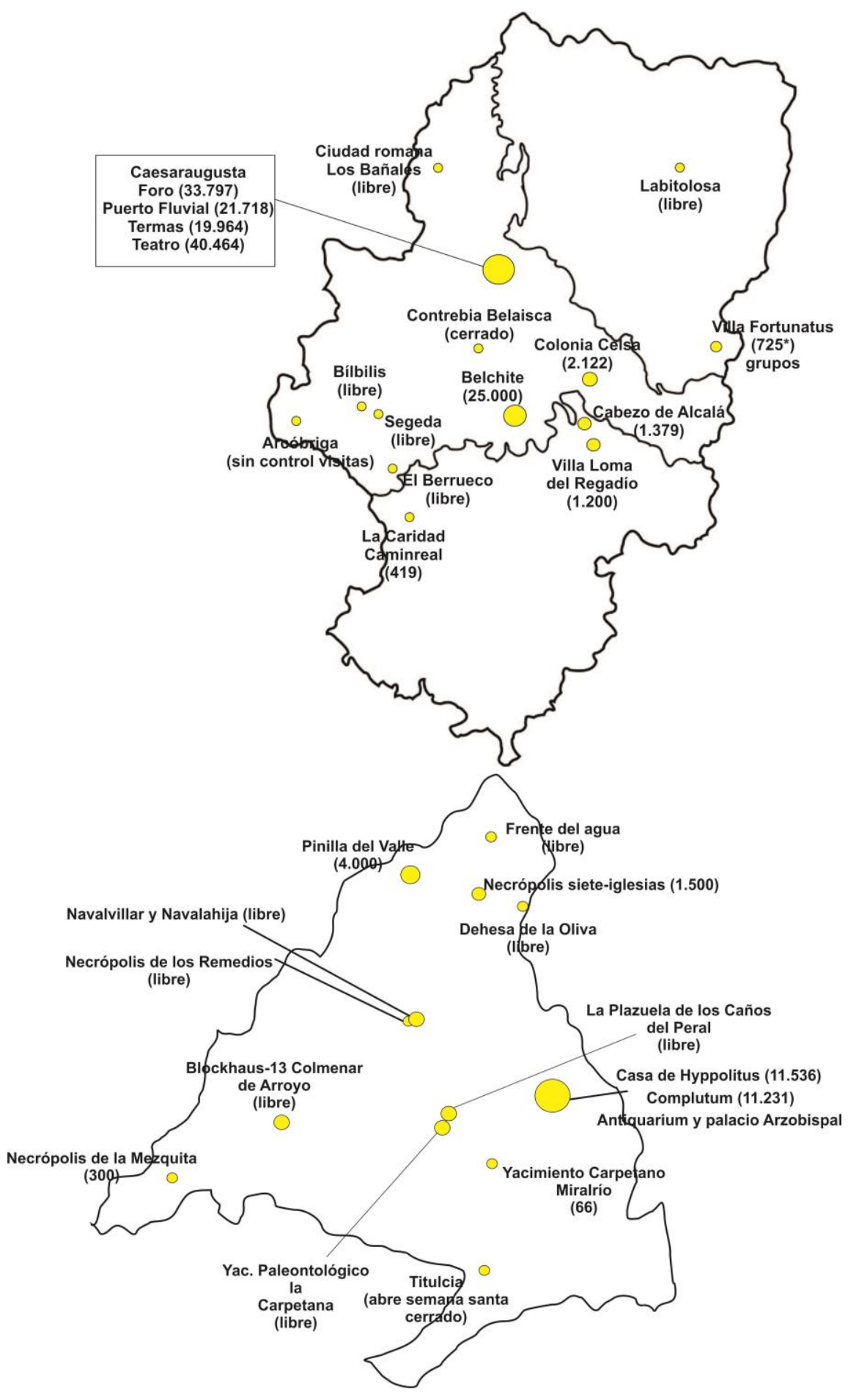



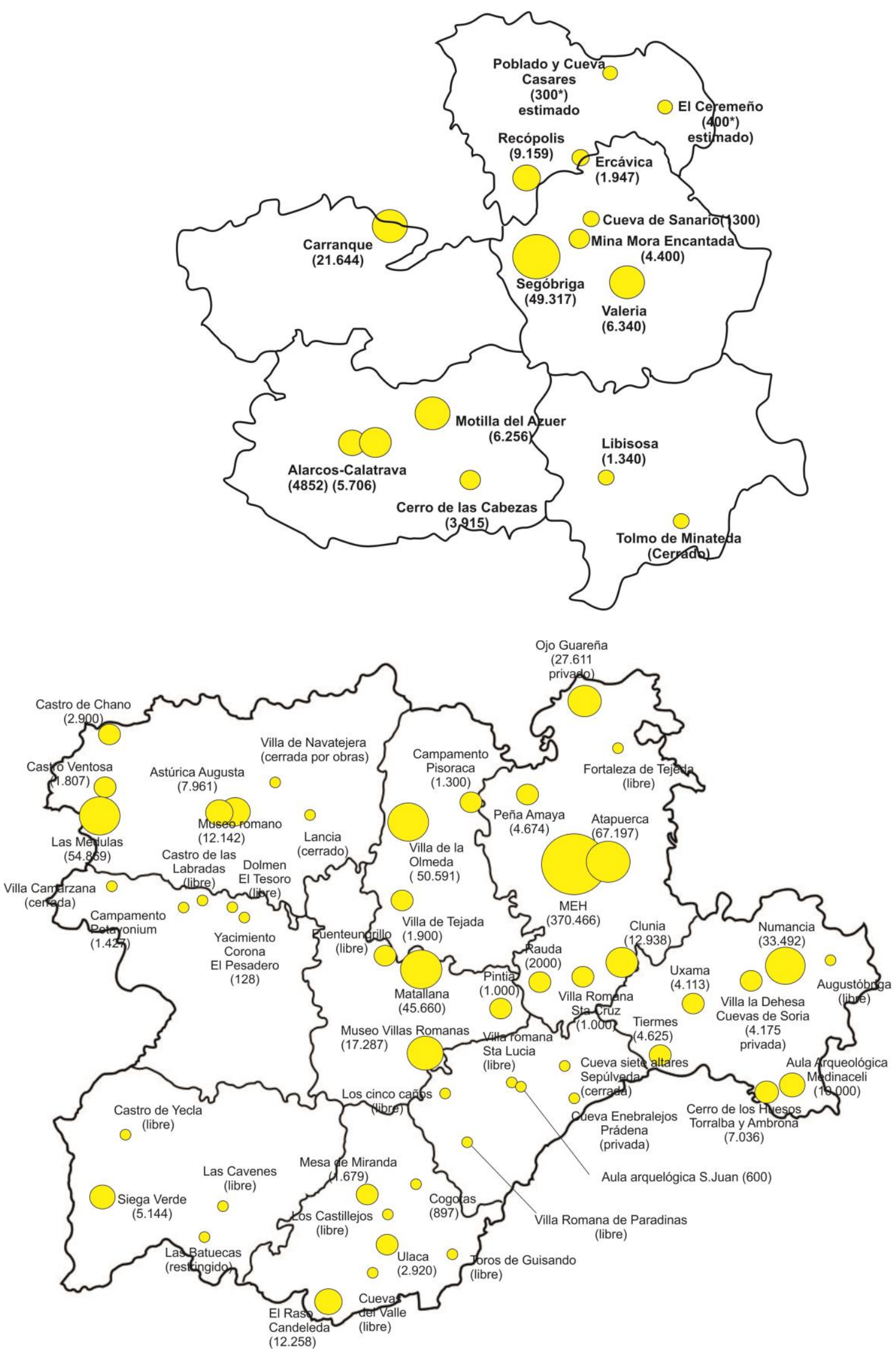

Elaboración propia. 
Figura 5. Norte de España: Galicia, Asturias, Euskadi, Navarra, Cantabria y La Rioja.

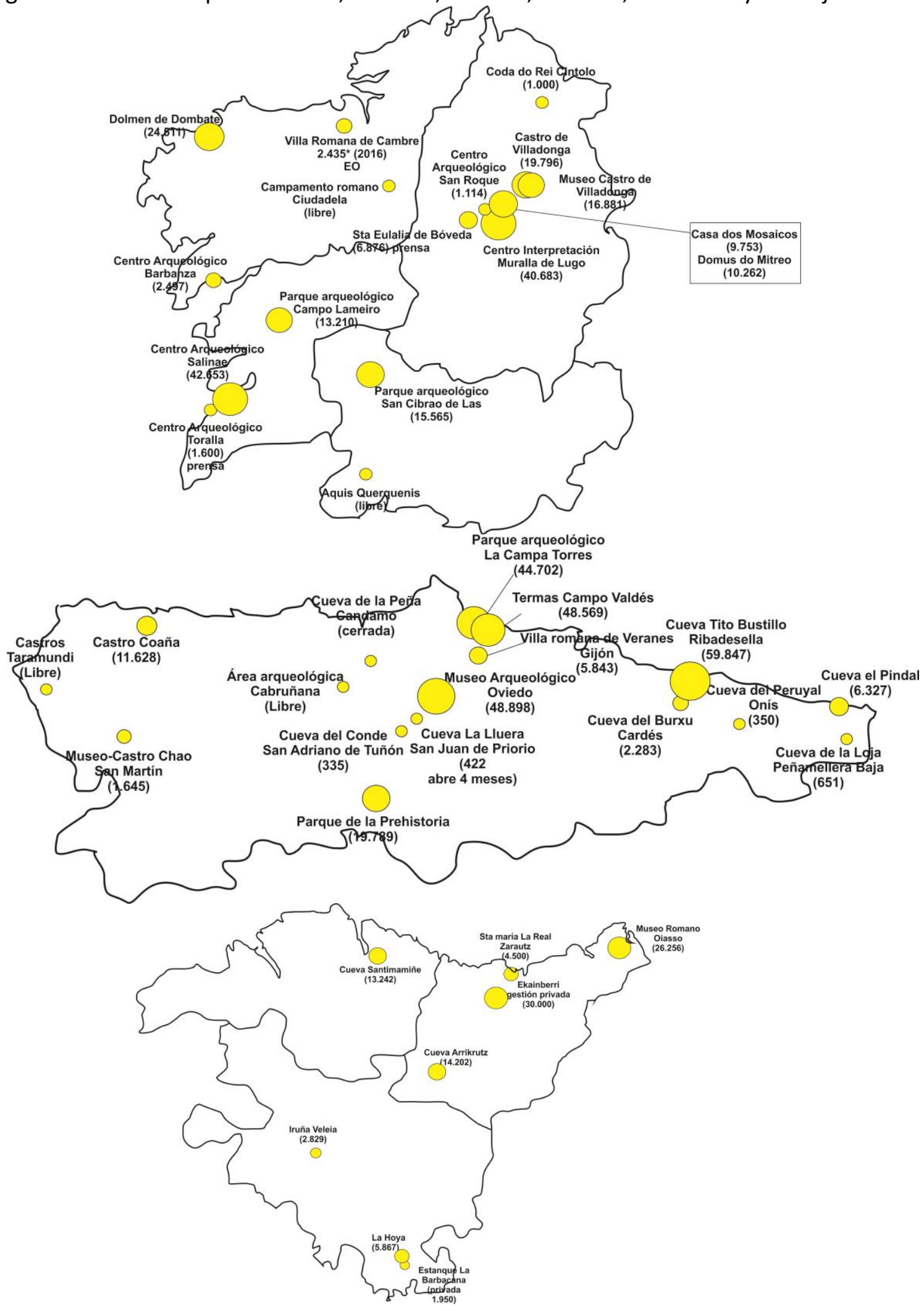




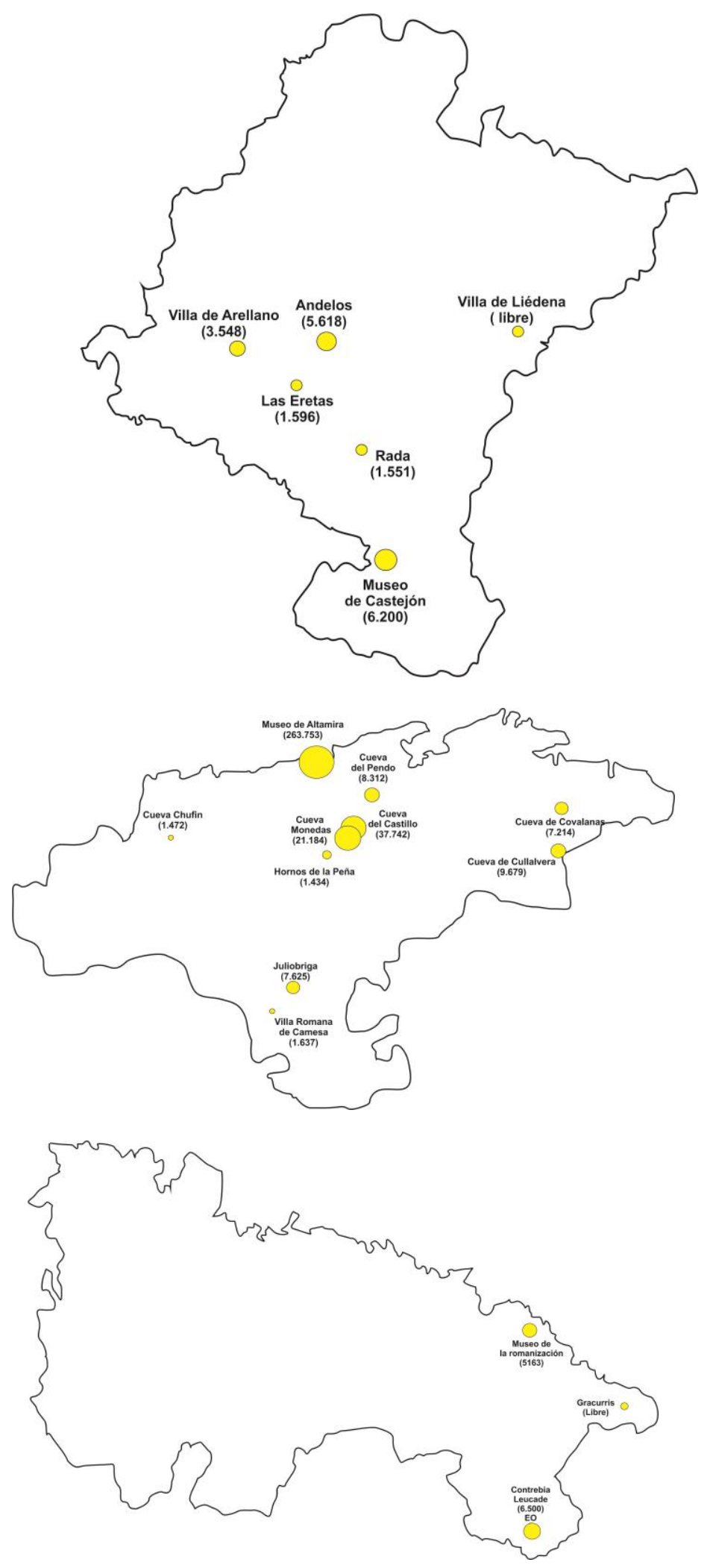

Elaboración propia 
Figura 6. España oriental: Comunidad Valenciana, Cataluña.

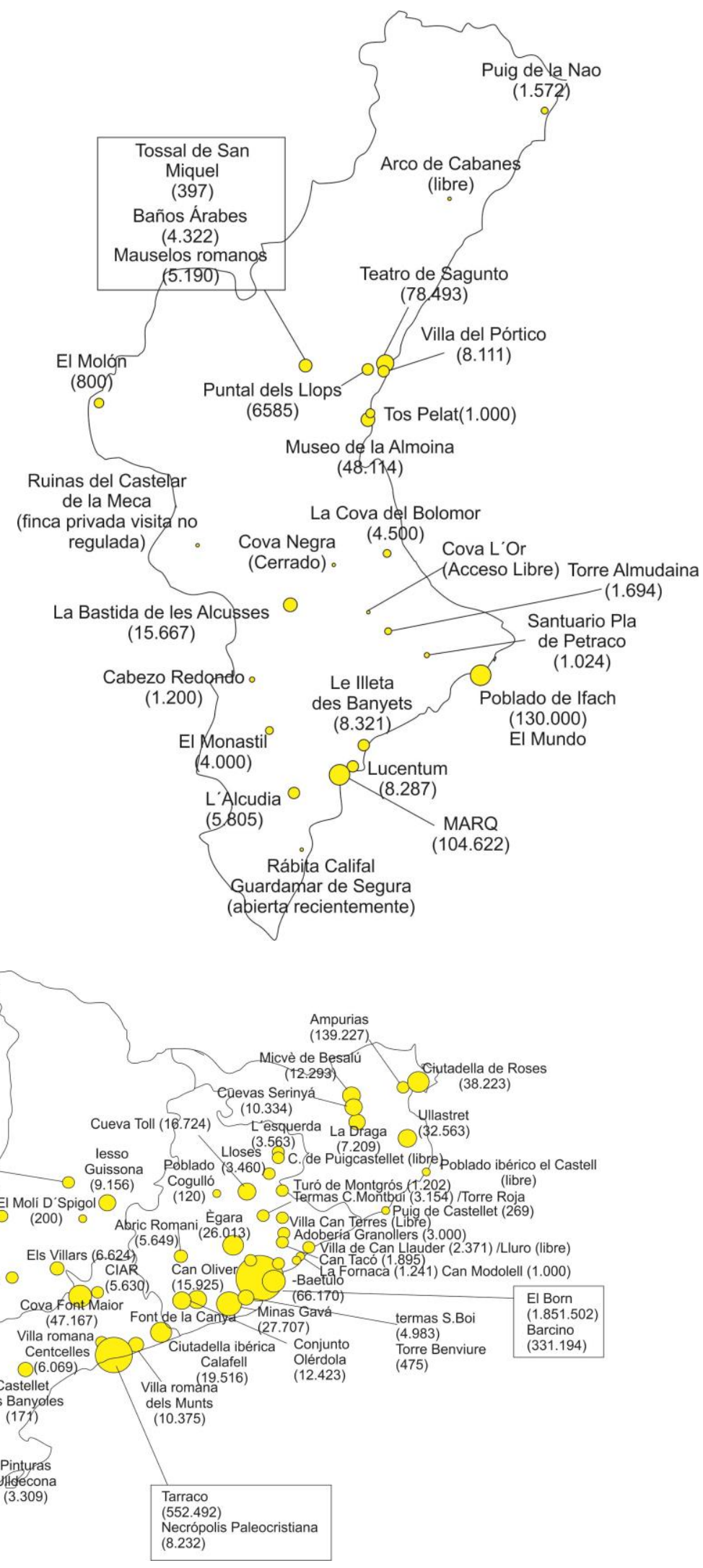

Elaboración propia. 
Figura 7. España extrapeninsular: Canarias y Baleares. Ciudad autónoma de Ceuta.
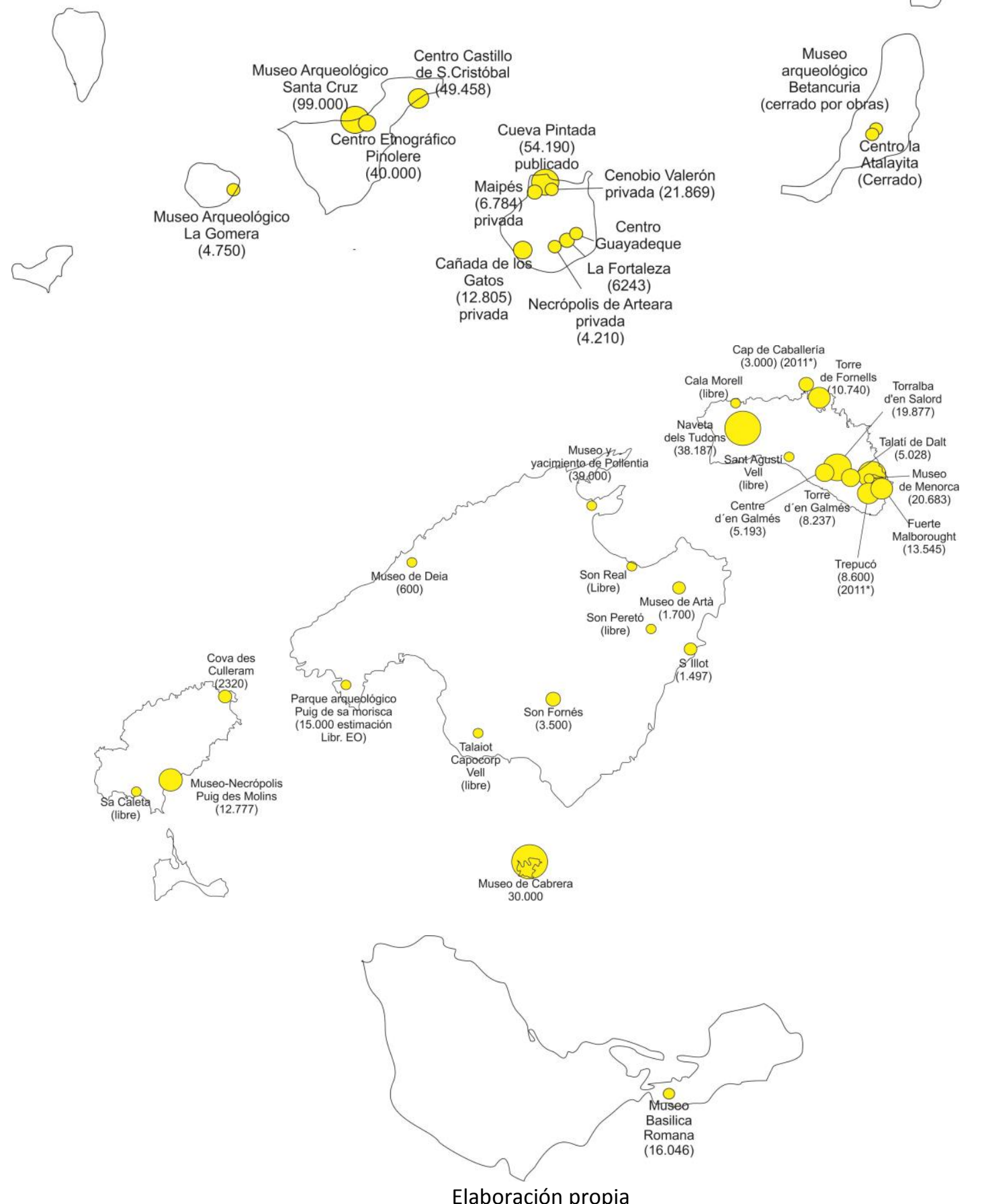


\section{ANÁLISIS DE LOS RESULTADOS}

En función de los resultados mostrados en los mapas anteriores sobre el arqueoturismo en España, podemos destacar las siguientes características:

1. Existe una oferta abundante y bien distribuida en nuestro país.

2. El arqueoturismo se desarrolla en mayor medida como complemento a otros turismos, especialmente en áreas costeras.

3. Tiene mayor volumen de visitantes en entornos urbanos.

4. Los yacimientos con elementos monumentales tienen un poder de atracción mayor, especialmente los restos romanos.

5. Existen contrastes notorios en la inversión y adecuación de yacimientos y centros arqueológicos entre CCAA, lo que revierte a su vez en los resultados turísticos.

6. Existe una diversidad de regímenes de gestión incomunicados entre sí, razón que evita que se vertebren circuitos y flujos de visitantes que retroalimenten el arqueoturismo.

7. Incipiente acceso del ámbito privado a estos recursos culturales.

8. Proporcionalidad del impacto de un yacimiento en relación al turismo de un lugar.

Acerca de las motivaciones para visitar estos espacios se han propuesto dos categorías llamadas factores de empuje y atracción (Recuero et al., 2010, p.102). En el primer aspecto se reunirían las características evocadoras del yacimiento arqueológico mientras que en el segundo campo se centran en elementos de infraestructura. Considerando acertada dicha categorización debemos añadir otros componentes como la presencia mediática, oferta de servicios, monumentalidad o el sistema de referencias y recomendaciones (especialmente online).

España cuenta con ocho yacimientos arqueológicos declarados Patrimonio de la Humanidad (Tresserras, 2004) con la firme propuesta de algunos candidatos a engrosar dicha nómina; el Consell Insular de Menorca propone 25 (Bagur, 2013), La Junta de Andalucía apuesta por el conjunto de Medina Azahara (Haba, 2016) y en Castilla y León por Numancia (Matute, 2016). En este sentido, parece que dichos enclaves, por su prestigio e interés, pueden ser razón suficiente de motivación para el consumidor cultural, principal estímulo para un $25,4 \%$ de los españoles (IET, 2007). Sin embargo, la realidad de los yacimientos arqueológicos es diversa y atiende, en gran medida, como complemento a destinos de intereses diversos o un público aún minoritario. La oferta turística del arqueoturismo es abundante y está en crecimiento por la propia naturaleza de los restos y la obligación de las administraciones en su conservación. Pese a las campañas de excavación, es unánime la postura de estas instituciones en la imposibilidad de musealizar en todos los casos (Morère y Jiménez, 2007, p.128). Pese a ello, un 12,1\% de los museos son de materia arqueológica (MECD, 2016:6). En los últimos años han sido editadas guías de viajes arqueológicos para informar de un turismo que adolece de escasa visibilidad y promoción (véase Del Rey, 2013 y Paz, 2015).

Los yacimientos y centros arqueológicos más visitados se sitúan normalmente en ciudades populosas y capitales de provincia. No en balde, el turista cultural suele ser residente en una metrópolis o gran ciudad, de mediana edad, de considerable nivel educativo, medio o alto nivel adquisitivo y que viaja con asiduidad (Romero, 2001:101). También la visita de centros escolares revierte en un aumento de las cifras en estos enclaves, 
por lo que podemos concluir que la accesibilidad es clave. Este no deja de ser un enorme desafío para un patrimonio que se sitúa normalmente en territorios rurales con escasas vías de comunicación y sin presencia de transporte público. Tampoco es posible el desarrollo de un polo turístico entorno a un yacimiento arqueológico, si no se cuentan con unas infraestructuras mínimas de servicios de hostelería y hospedaje próximos.

Es un hecho palpable en el mapa, el poder de atracción de los conjuntos monumentales, caso de las ciudades romanas de Mérida, Cartagena, Baétulo y Segóbriga. También las cuevas de pinturas rupestres en el norte y levante, aunque en menor proporción, representan un influjo importante de turistas. Cabe mencionar el interés generado por un escenario de época contemporánea, Belchite (Zaragoza), en una comunidad autónoma con escasa incidencia del arqueoturismo.

La propia densidad de yacimientos y el volumen de actividad turística es una prueba del interés con que han afrontado éste tipo de patrimonio las diversas administraciones. La planificación y promoción de los yacimientos arqueológicos es una tarea a largo plazo que ha tenido resultados desiguales en función de la latitud. En este sentido, cabe citar, la postura que han defendido las diversas comunidades autónomas del país. Desde la capital se apuesta por un Plan de yacimientos visitables basado principalmente en la señalética, asumiendo la musealización de los espacios sin precisar un mantenimiento de personal. Este es el caso de la mayor parte de su patrimonio con algunas excepciones como Complutum, y la necrópolis de Sieteiglesias, de gestión local y Pinilla del Valle, de ámbito privado. Cabría preguntarse si una comunidad con el potencial emisor de turistas como Madrid no podría absorber parte de los viajeros que emite en su propio turismo interno con una inversión más ambiciosa de servicios. En Castilla y León, por el contrario, se apuesta por algunos yacimientos señeros con grandes instalaciones como en Las Médulas, el Museo de las Villas Romanas, La Olmeda o Atapuerca. Varias de ellas a través de convenios con fundaciones.

El modelo de Andalucía asume las competencias en la gestión de los grandes yacimientos arqueológicos de la Comunidad, repercutiendo una pequeña cantidad como entrada o de forma gratuita a los ciudadanos de la UE. Es probable que esta gratuidad influya decisivamente en la afluencia de público nacional a los yacimientos. El modelo canario, ha sido pionero en la gestión privada de enclaves arqueológicos. En este sistema destaca la diversificación de servicios, introducción del marketing y promoción. Es notable el aporte de visitantes de origen extranjero en estos espacios en relación a su escasa incidencia en lugares homólogos del interior peninsular.

En Cataluña, la densidad de yacimientos demuestra la apuesta por el turismo arqueológico como complemento al producto de sol y playa con un volumen muy notable de público. De este modo, se permite descongestionar la demanda excesiva y el umbral de carga máxima en otras ofertas culturales sobresaturadas de Cataluña. En Murcia, es destacable la preferencia por la gestión local, sin una institución de carácter supramunicipal que acapare los principales referentes patrimoniales, un caso casi único en la península. Las oficinas locales de turismo suelen ser las responsables de aportar servicios de guía de carácter arqueológico en este modelo.

Por último, en Valencia, dentro de la profusión de patrones de gerencia arqueológica, destaca la fundación universitaria de investigación arqueológica en la Alcudia de Elche. En 
este patrón es la investigación, la docencia y la difusión científica la que marca la diferencia en beneficio tanto del bien como del alumnado.

Aunque ya ha sido previamente percibido, la pluralidad de modelos de gestión ha repercutido en la creación de un mercado sobre el turismo arqueológico. La gran mayoría de espacios históricos son tutelados por entidades autonómicas, diputaciones, ayuntamientos, oficinas de turismo, consorcios, fundaciones y empresas. Esto se debe a que el patrimonio histórico era gestionado desde entidades públicas mientras que el turismo se nutre de agentes privados (Velasco, 2013). La confluencia entre patrimonio y turismo es aún una asignatura pendiente en nuestro país. Cabe citar como ejemplo de convergencia la reciente creación de la Red de Villas Romanas de Hispania, una plataforma que aglutina la promoción de una red de yacimientos temáticos pertenecientes a siete autonomías.

Para concluir, debemos ser conscientes de que las cifras netas de visitantes no pueden servir como único indicador del impacto de los yacimientos y espacios arqueológicos en el turismo de un lugar concreto. Debemos atender a la proporcionalidad de la aportación de un enclave patrimonial al conjunto de visitantes de un lugar. En este sentido, valga la comparativa de la contribución de Baelo Claudia (151.624) en los 2.296.546 visitantes que pernoctaron en la provincia de Cádiz en 2015 (AEA, 2015) frente a la Villa de la Olmeda (50.591) respecto a Palencia, con 340.760 (BTCYL, 2015). Cualitativa y cuantitativamente en proporción, el segundo ejemplo aporta más al turismo que el primero, pese a que su cifra neta sea inferior. A continuación detallamos los índices de impacto de los yacimientos arqueológicos en el conjunto turístico nacional.

\section{CONCLUSIONES}

El hecho de que 8.926.568 personas hayan visitado yacimientos y centros de interpretación afines en el año 2015 habla de la madurez de éste recurso patrimonial. El $16,6 \%$ de las personas que suelen realizar actividades culturales visitaron, al menos, un yacimiento arqueológico en el último año, tres puntos y medio porcentuales más que en el mismo período en 2007, lo que apunta su crecimiento (MECD, 2015, p.191). El interés por otros campos de la cultura de los visitantes de centros arqueológicos es un rasgo importante que puede ser orientado a vertebrar colaboraciones con otros campos como la literatura, los museos o las artes escénicas para retroalimentarse.

A tenor de éstas cifras podemos aventurar que ya no se trata de un turismo minoritario, sino que lugares consagrados conviven con otros de gran desarrollo potencial. Los principales destinos del turismo arqueológico son, en volumen descendente, Cataluña, Andalucía, Extremadura y Castilla y León, copando el $46 \%$ del mercado nacional. Es reseñable la tendencia del crecimiento del volumen de visitantes desde el interior peninsular hacia las áreas periféricas y costeras.

La principal preocupación dentro de éste ámbito debe ser el respeto por la capacidad de carga máxima de visitantes de un lugar para no comprometer su conservación (Pociovalisteanu y Niculescu, 2010). En este sentido, es relevante que el $40 \%$ del impacto del arqueoturismo en España se nutre de tan sólo 16 yacimientos (Tabla 3), por lo que es necesaria una política comprometida de promoción en enclaves menores. La incorporación de agentes privados y profesionales externos podría ser un buen acicate como nos ilustra la progresión del turismo activo en España (Araújo et al., 2012). 
Por otra parte, los diferentes mapas evidencian una realidad que debe tenerse en cuenta de cara a elaborar estrategias e inversiones que potencien un enclave arqueológico como recurso turístico. Muchos de los espacios visitables tienen unas cifras de visitantes muy pequeñas e incluso ínfimas, redundando en un déficit que puede poner en riesgo la sostenibilidad de un centro cultural. El diseño de un proyecto cultural previo permite, entre otros beneficios, optimizar recursos, orientar las acciones desde el inicio, establecer prioridades, reflexionar sobre la situación de partida y ejercer un control y seguimiento (Roselló, 2004). Como apuntan Santana y Serrat (2005, p.544), una de las diferencias más importantes entre los ambientes museísticos más avanzados y los más tradicionales es la cultura de la planificación.

La improvisación y la falta de un plan de gestión es la tónica habitual en el patrimonio arqueológico. Esto se debe en gran medida a la disociación entre el papel del arqueólogo y del gestor cultural. Dentro de la gestión del patrimonio se suceden las siguientes fases; conocer, planificar, controlar y difundir (Querol, 2010, p.51). La creación de una estrategia integral que permita la sostenibilidad viene definida a partir de un documento o Plan de gestión, similar al del mundo de los museos, llamado plan museológico. Nosotros hemos propuesto un modelo en un estudio previo en el que se combinan herramientas del marketing y la comunicación (Fernández, 2017). Desde este artículo abogamos por la multidisciplinaridad en la ejecución de un proyecto arqueológico, con fuerte base científica, herramientas de conservación, gestión, seguimiento y difusión, en el que participen profesionales de diversos sectores.

En aras de asesorar a los profesionales encargados de la custodia, preservación y difusión de los yacimientos debería crearse un observatorio nacional y sus respectivos autonómicos que formasen a los profesionales y atendiesen la viabilidad de los centros arqueológicos. Asimismo, sería aconsejable la creación de un documento con indicadores que permitiese a los responsables evaluar las políticas de crecimiento de estos enclaves y efectuar medidas correctoras. Para iniciar este proceso es ineludible la transparencia en la información disponible.

El perfil del visitante a espacios arqueológicos sigue siendo, a día de hoy, una materia pendiente de un análisis global propio. En la actualidad tenemos que acudir a las estadísticas del consumidor de productos culturales de conjunto o al turista con dicha motivación. Siguiendo a la fuente Balantur, del Instituto de Turismo de España, el perfil socio demográfico es muy similar en todos los mercados: se trata de asalariados de cargo medio, con edades comprendidas entre los 25 y 44 años, con estudios superiores y viajan en pareja.

En definitiva, este campo comienza a dejar de considerarse un tipo de turismo alternativo para insertarse en los circuitos habituales. La particularidad del patrimonio es la prioridad de su uso compatible con su conservación, por lo que las diversas administraciones deberán elaborar estrategias en cada caso para que los yacimientos supongan un dinamizador de una región y su identidad sin menoscabar su integridad. Como conclusión a los datos analizados, podemos afirmar la dependencia turística de algunos territorios respecto al patrimonio arqueológico, caso de Mérida, Tarragona y Burgos, por citar algunos. Otras comunidades como Cataluña $(8,6 \%)$, teniendo recursos turísticos de sol y playa y culturales, han apostado también por la arqueología como vía de redirección de una 
demanda excesiva en sus núcleos principales. En otros casos como Navarra $(0,63 \%)$ y Madrid (0,2 \%) existe menor inversión en la puesta en valor de este tipo de recursos.

El futuro del arqueoturismo deriva de una mayor implicación de todos los agentes implicados, administraciones, sociedad civil y empresas, creando valor integrado en el territorio. Suscribimos la siguiente frase del Manual de gestión del patrimonio mundial cultural de la Unesco "la complejidad inherente al patrimonio debería inducir a la sociedad a gestionarlo con un criterio holístico en vez de limitarse a conservar estructuras específicas, como ocurría en el pasado." (2014).

\section{REFERENCIAS BIBLIOGRÁFICAS}

Anuario estadístico de Andalucía (2015). Viajeros entrados en establecimientos hoteleros según país de procedencia por provincia de alojamiento. Instituto de Estadística y Cartografía de Andalucía.

Anuario de estadísticas culturales 2015 (2015). Ministerio de Educación, Cultura y Deporte. Subdirección General de Estadística y Estudios, Secretaría General Técnica. Madrid.

Araújo, N, Fraiz, J.A y Paül, V. (2012). El turismo activo como modalidad turística en expansión. Análisis de la oferta de turismo activo en España. Contabilidad y Negocios. Universidad Católica del Perú. Revista del Departamento Académico de Ciencias Adminsitrativas. Vol 7, №13, 59-70.

Bagur, J. (2013). Los 25 yacimientos propuestos para Patrimonio de la Humanidad en Menorca. Menorca.info. 02.08.2013.

Balance del Turismo. Resultados de la actividad turística en España (2013). Ministerio de Industria, Energía y Turismo. Instituto de Turismo de España. Madrid.

Ballart, J y Tresserras, J. (2001). Gestión del patrimonio cultural. Colección Ariel Patrimonio. Barcelona.

Boletín de coyuntura turística de Castilla y León. Resultados 2015 (2015). Consejería de Cultura y Turismo de Castilla y León.

Chávez, M.E, Pérez, F, Pérez, M.E, Soler, J, Goño, A y Tejera, A (2009-2010). El proyecto de San Blas (San Miguel de Abona, Tenerife): Revalorización del Patrimonio Arqueológico. Tabona. Revista de Prehistoria y Arqueología. Universidad de La Laguna, 18, 121-133.

Del Rey, L. (2013). Guía arqueológica de la Península Ibérica. España. De las colonizaciones a la caída del Imperio Romano. Editorial: Luis del Rey Schnitzler.

Díaz-Andreu, M. (2014) Turismo y arqueología. Una mirada histórica a una relación silenciada. Anales de Antropología, 48, Núm. 2, 9-39.

Encuesta de hábitos y prácticas culturales 2014-2015 (2015) Ministerio de Educación, Cultura y Deportes. Subdirección General de Estadística y Estudios, Secretaría General Técnica. Madrid.

Feilden, B.M y Jokilehto, J. (1993). Management guidelines for world cultural heritage sites. UNESCO. París.

Fernández, J. (2017). Gestión privada del patrimonio cultural: los casos del monasterio de Monsalud y la ciudad romana de Ercavica. Pasos, Revista de Turismo y Patrimonio Cultural. Vol. 15, 1, 121-137.

García, M y Calle, M. (2010). Uso y lectura turística de los grandes conjuntos arqueológicos. Reflexiones a partir del Estudio de Público de Medina Azahara/Madinat al-Zahara (Córdoba). Pasos, Revista de Turismo y Patrimonio Cultural. Vol. 8, 4, 609-626. 
Gillot, L. (2007) La mise en valeur du patrimoine archéologique comme outil de développement: L'exemple du développement touristique en République Arabe Syrienne. En C. Bataille y B. Schéou (Eds), Tourisme et Développement, 123-154. París.

González, M (1997) El vestigio como atracción del turismo, la interpretación como atracción del vestigio. AnMurcia, 13-14, págs. 289-299.

Haba, R. (2016). Mayor Zaragoza cree que Medina Azahara puede ser patrimonio de la humanidad. Diario de Córdoba (18/12/2016)

Instituto de Estudios Turísticos, IET (2007). Informe de hábitos turísticos de los residentes en España. Ministerio de Industria, Turismo y Comercio. Madrid.

López, I. y Navarro, E. (2007). El patrimonio arqueológico como dinamizador del turismo cultural: actuaciones en la ciudad de Málaga. Baetica. Estudios de Arte, 29, 155-171. Facultad de Filosofía y Letras. Universidad de Málaga.

Lugand, M. (2000). L'archéologie: vecteur de développement local? Les Dossiers d'archéologie, 250, 116-119.

Manzato, F. y Rejowski, M. (2007). Evaluación del potencial turístico de sitios arqueológicos. Estudios y Perspectivas en Turismo, 16, págs 72-95.

Martín, D, Castellanos, M y Oviedo, M.A (2010). A visitors' evaluation index for a visit to an archaeological site. Tourism Management, Volumen 31, № 5, 590-596.

Matute, J. (2016). El Ministerio de Cultura 'avanza' con Numancia. Diario de Soria $(25 / 05 / 2016)$.

Martin-Bueno, M. y Luesma, R. (2006). La arqueología como factor de desarrollo en la sociedad actual. Mainake, 28, 11-26.

McManamon, F.P (1991). The Many Publics for Archaeology. American Antiquity. Vol. 56, № $1,121-130$.

Moreno, A. (2013). La planificación y gestión turística de Siem Riep / Angkor (Camboya): Una aproximación desde el destino arqueológico considerando su relación con el parque arqueológico. Pasos, Revista de Turismo y Patrimonio Cultural. Vol. 11 N. ․ 1, 107-119.

Paz, J. (2015). Los mejores destinos arqueológicos en España. Anaya Touring. Colección Inspiración Viajera. Madrid.

Pedersen, A. (2002). Managing Tourism at World Heritage Sites: A Practical Manual for World Heritage Site Managers. UNESCO. París.

Peinado, A. (Coord). (2012). I Congreso Internacional. El patrimonio cultural y natural como motor de desarrollo: investigación e innovación. Universidad Internacional de Andalucía. Jaén.

Pociovalisteanu, D.M. y Niculescu, G. (2010) Sustainable Development Through Eco-Cultural Tourism. European Research Studies Journal, vol. XIII, 2, 149-160.

Ponce, G. y Rubio, L. (Coord) (2013). Gestión del patrimonio arquitectónico, cultural y medioambiental. Enfoques y casos prácticos. Alicante: Universidad de Alicante; México: Universidad Autónoma Metropolitana.

Poor, P.J. y Smith, J.M. (2004). Travel Cost Analysis of a Cultural Heritage Site: The Case of Historic St. Mary's City of Maryland. Journal of Cultural Economics, 28, 3, 217-229.

Pokotylo, D. y Guppy, N (1999). Public Opinion and Archaeological Heritage: Views from Outside the Profession. American Antiquity, Vol. 64, № 3, 400-416.

Querol, M.A. (2010). Gestión del patrimonio cultural. Akal. Barcelona.

Raposo, J (2001) Sitios arqueológicos visitáveis em Portugal. Al-Madan IIa série, 10, 107-157. 
Recuero, N, Blasco, M.F y García, J (2010) Identifying motivations of archaeological sites visitors. Cuadernos de Estudios Empresariales, 21, 97-113.

Reynaud, J.F. (1990) Mise en valeur des sites archéologiques. Nouvelles de l'archéologie, 41. 47-52.

Rodríguez, I, Ruiz, J.I. y Mínguez, C. (2015). Análisis de la visita pública a la Necrópolis Romana de Carmona entre 1885 y 1985. Archivo Español de Arqueología, 88, 263-282.

Romero, C. (2001). Ciudad, cultura y turismo: calidad y autenticidad. Revista de Patrimonio Histórico. Instituto Andaluz de Patrimonio Histórico. Consejería de Cultura de Andalucía. № 36, 100-109.

Roselló, D. (2004). Diseño y evaluación de proyectos culturales. Ariel. Barcelona.

Santana J. y Serrat, N. (2005). Museografía didáctica. Ariel Barcelona.

Traverso Cortés, J. (1996) Comunicación interpretativa: variable clave en el marketing-mix de las empresas de turismo rural. Estudios Turísticos, 130, 38.

Tresserras, J (2004). El arqueoturismo o turismo arqueológico: un paso más para la valorización del patrimonio arqueológico. Boletín GC: Gestión Cultural № 9, Turismo Arqueológico, 2-7.

UNESCO (2014). Manual de gestión del Patrimonio Mundial Cultural. París.

Velasco, M. (2009). "Gestión turística del patrimonio cultural: enfoques para un desarrollo sostenible del turismo cultural". Cuadernos de Turismo, no 23, 237-254.

Velasco, M. (2013). Conceptos en evolución: turismo, cultura y turismo cultural. En Pulido, Jl, De la Calle M y Velasco, M (Coord) Turismo cultural. Síntesis.

Wager, J. (1995). Developing a strategy for the Angkor World Heritage Site. Tourism Management, Volumen 16, № 7, 515-523. 